\title{
Comparison of Male and Female Response Behaviour on Minnesota Multiphasic Personality Inventory-2
}

\author{
Dr. Hayfa Tayseer Elbokai \& Dr. Aziz Ahmad Alrhamneh \\ Special Education Dep., Al- Balqa' Applied University, Jordan \\ Tel: 962-77-966-1242Ｅ-mail: helbokae@scs-net.org
}

Received: November 4, $2010 \quad$ Accepted: December 10, $2010 \quad$ doi:10.5539/ass.v7n5p207

\begin{abstract}
This study aimed to compare the response behaviour of male and female on the second edition of Minnesota Multiphasic Personality Inventory, and to draw faking good and bad profiles for them.

The researchers applied the MMPI-2 on 850 subjects; their age ranged from 17-30 years old, which chosen randomly from Al-Balqa' Applied Universities' different colleges.

After using the equation of faking good and bad, the sample consisted of 160 subjects, $/ 61 / \mathrm{males}$ and/ 99/ females; they were chosen deliberately from 850 subjects.

The authors used mean and standard deviation to draw faking good and bad profiles for male and female separately.

The study has achieved number of results which are summarized into the following points:

1- The reason behind of students' faking good might be their choice of the option 'false' for most test.

2- The reason behind of students' faking bad might be their choice of the option 'true' for most test.

3- Similarity exists between the profiles' forms of faking good for males and females separately and the other studies which applied a close studies to the current one.

4- Similarity exists between the profiles' forms of faking bad for males and females separately and the other studies which applied a close studies to the current one.

Current research recommendations for future research are provided.
\end{abstract}

Keywords: Minnesota multiphasic personality inventory, Response behaviour, Male and female

\section{Introduction}

Minnesota Multiphasic Personality Inventory is considered to be one of the most important objective inventories and its most widely used psychological test. With over 8,000 books and articles published on it. Its international use is extensive, including over 115 translations and use in over 65 different countries. This inventory is located within self-assessment inventories. Therefore, sometimes persons completing the MMPI-2 are motivated to deny problems and to appear better-off psychologically than is in fact the case. In its most blatant form this tendency is referred to as faking good. Those people scored considerably higher on the $\mathrm{K}$ scale raw score than on the $\mathrm{F}$ scale raw score can serve as a useful index for detection fake good profiles. When such an index number was negative and greeter than 9, a profile was likely to be product of a fake good response set. Carson (1969) suggested that a cutoff score of -11 yielded more accurate identification of fake good MMPI profiles.

On the other hand, some persons may be motivated to present an unrealistically negative impression when completing the MMPI-2. This response set often is referred to as faking bad. Those people scored considerably higher on the $\mathrm{F}$ scale raw score than on the $\mathrm{K}$ scale raw score can serve as a useful index for detection fake bad profiles. Gough (1950) and Meehl (1951) indicated that when such an index number was positive and greeter than 9, a profile was likely to be product of a fake bad response set. Carson (1969) suggested that a cutoff score of +11 yielded more accurate identification of fake bad MMPI profiles (Graham, 2000, p.38)

Although the authors of the MMPI expected the empirical keying procedure used in the MMPI to make such distortions less likely than in earlier face-valid inventories, they recognized the importance of assessing test-taking attitudes. The four validity indicators developed specifically to assess test-taking attitude with the 


\section{MMPI-2}

Many studies circling around validity scales and the inventory responsiveness methods (the good and the bad) are showed up.

This current research is one of many researches including attempts to study the two methods of this inventory responsiveness (negative and positive) and to know the profiles' form for each one of the two methods for males and females.

\section{Research problem}

It is necessary that the test is taken seriously and is applied validly by the examinee in order to gain scrutinized and useful information through its application. This is not always the case; for some examinees do not answer the test validly and may not take its application seriously which means that they follow various responsiveness methods while applying the test. For that, validity scales are considered to be one of the important scales in the test for being able to discover orientations and methods of responsiveness which the examinee may use.

One deviant response set involves a random or near-random response to the test items. A person may respond in a clearly random manner or may use an idiosyncratic response pattern such as marking every block of eight items as "true true, false false, true true, false false" or every block of six items as" true false, true false, true false, and repeating this pattern with each such subsequent block. There are various reasons why persons respond randomly to the test items. Sometimes they cannot read well enough to understand the items but are reluctant to inform the examiner that this is the case. Other times test takers are confused or uncooperative because they do not want to take the test but feel that they cannot directly refuse to do so.

In addition to these persons who answer the test randomly, other persons give a negative image about themselves more than what they really are; they answer the test items oriented towards the satisfying direction exaggeratedly (this what we call faking bad). Many factors lie behind such behavior: appealing sympathy from others, giving negative image about self-essence and exaggerating symptoms they suffer from.

Finally, there are some persons give positive image about themselves more than what they really are; their answers of the test items are better than their condition in reality (this we call faking good). One of the reasons of this method is that they are trying to deny problems they suffer from.

Graham (2000) mentioned that there are many and various studies about what was mentioned previously about responsiveness methods. He cited more than 50 studies in which the study of the various responsiveness methods, taken by the examinee, such as random answering and faking good and faking bad are proceeded. These studies also included the drawings of profiles specific for each method (Graham, 2000, pp, 42-59).

This current study is considered to be one of the studies that stopped at the two methods of responsiveness, faking good and faking bad, of the MMPI-2 and the knowledge of the profiles' forms of these two methods. Through the application and the correction of this inventory the researchers noticed that there are positive or negative responsiveness methods obtained by some students. This make them wondering about the reason of some students' attempts to fake good or to fake bad. From here, the idea of the current research begun. This encouraged them to study methods of responsiveness of this inventory as an attempt from them to know the reason behind students' faking, also to know the profiles' forms for male and female separately.

\section{Research Importance}

The importance of this research springs from the following points:

1- The importance of Minnesota Multiphasic Personality Inventory whereas it is considered to be one of the important inventories for its ability to discover some of the methods of responsiveness such as, faking good and faking bad.

2- The importance of studying the methods of responsiveness of this inventory which is considered to be the premier study on both sides: the local and the Arabic.

3- The importance of drawing the profiles' forms of faking good and bad for males and females separately.

\section{Research Purposes}

1- Studying the first responsiveness method which is represented in Faking Good.

2- Studying the second responsiveness method which is represented in Faking Bad.

3- Drawing the Minnesota Inventory's profiles of the first responsiveness method for males and females separately. 
4- Drawing the Minnesota Inventory's profiles of the second responsiveness method for males and females separately.

\section{Research Questions}

The current research is seeking for answering the following questions:

1 - What is the reason behind students' faking good?

2- What is the reason behind students' faking bad?

3- What is the form of Faking Good profiles for males and females separately?

4- What is the form of Faking Bad profiles for males and females separately?

\section{Research Sample}

The MMPI-2 was applied on 850 subjects; their age ranged from 17-30 years old, which chosen randomly from Al-Balqa' Applied Universities' different colleges.

After using the equation of faking good and bad, the sample consisted of 160 subjects, /61/ males and/ 99/ females; they were chosen deliberately from 850 subjects.

This sample is the total number of students who faked one of the two pretensions: the good or the bad.

The details of this sample will be explained as follows:

a- Number of students who faked good was 55 students, 20 students were males and 35 students were females.

b- Number of students who faked bad was 105 students, 41 students were males and 64 students were females.

c- Number of the rest of the sample was 590 students; faking good and faking bad were not discovered from the results.

\section{Study Procedure}

Analytical, descriptive procedure was followed in order to study Minnesota Multiphasic Personality Inventory's responsiveness methods and to draw profiles for each of the two responsiveness methods for males and females.

\section{Research Instrument}

Minnesota Multiphasic Personality Inventory second edition, published in 1989, was used. This edition consisted of 567 "true" or "false" items. This inventory contains a large number of scales but the reliance was on two of them: validity scales which consist of three scales 1- Lie 2-Infrequency 3-Correction; and the clinical scales which are:

Scale1 (Hypochondriasis): was developed to identify patients who manifested a pattern of symptoms associated with the label of hypochondriasis. The syndrome was characterized in clinical terms by preoccupation with the body and concomitant fears of illness and disease.

Scale 2 (Depression): was developed to assess symptomatic depression. Poor moral, lack of hope in the future, and general dissatisfaction with one's life situation.

Scale 3 (Hysteria): was developed to identify patients who were having hysterical reactions to stress situations.

Scale 4 (Psychopathic Deviate): was developed to identify patients diagnosed as psychopathic personality, asocial or amoral type.

Scale 5 (Masculinity-Femininity): was developed originally to identify homosexual invert males.

Scale 6 (Paranoia): was developed to identify patients who were judged to have paranoid symptoms such as ideas of reference, feelings of persecution, grandiose

self-concepts, suspiciousness, excessive sensitivity, and rigid opinions and attitudes.

Scale 7 (Psychasthenia): the obsessive-compulsive disorder probably is closest to the original psychasthenia label.

Scale 8 (Schizophrenia): was developed to identify patients with diagnoses of schizophrenia. This category includes a heterogeneous group of disorders characterized by disturbance of thinking, mood, and behaviour.

Scale 9 (Hypomania): was developed to identify psychiatric patients manifesting hypomanic symptoms. Hypomaina is characterized by elevated mood, accelerated speech and motor activity, irritability, flight of ideas, and brief periods of depression.

Scale 10 (Social Introversion): this scale was designed to assess person's tendency to withdraw from social contacts and responsibilities. (Hathaway \& McKinley, 1989, pp.28-30) 


\section{Previous Studies}

1- Parker's study in Alabama in 1991:

Patterns of response to the MMPI-2 that typify deliberate deception of others (faking good) were studied using 100 undergraduates at the University of Alabama who were given extra cause credit for participation in the study. Female constituted $73 \%$ of the final subjects pool. Each subject was given the MMPI-2 test booklet and two sets of answer sheets. subjects were asked to complete the MMPI-2 anonymously, first trying to impress a potential employer, and then answering honestly with first reactions.

Discriminate analysis and regression identified $83 \%$ of the normal MMPI- 2 answers and $78 \%$ of fake good response sheets. Chi square and additional analyses resulted in anew scale that identified variable. Cross-validation with an additional analysis resulted in anew scale that identified $89 \%$ of normal responses and $90 \%$ of fake good responses. Gender was not found to be a significant demonstrates a new method of assessing a deliberate fake good response set. (Parker, 1991, pp.1-13).

2- Wetter, et, al. study in Kentucky in 1992:

Effects of random responding and malingering on MMPI-2 validity scales were studied with 173 graduate and undergraduate university of Kentucky (Lexington) students. Inconsistent responding and malingering produced significant elevations on the validity scales, with the dissimulation scale appearing sensitive enough to warrant further research. (Wetter, et, al., 1992, p. 369-74)

3- Austin's study in America in 1992:

The efficacy of 5 scales of the MMPI- 2 in detecting fake good, fake bad, and honest profiles was investigated for 110 variance suggests that these validity scales useful. (Austin, 1992, pp. 669-74)

4- Lamp, et, al. study in America in 1994:

The impact of on detailed information on closed head injury(CHI) and MMPI-2 validity scales on malingering psychological symptoms of CHI on the MMPI-2 was studied in an analog experiment with 270 undergraduates results suggest the impact such coaching on simulation of CHI.(Lamp, et.al., 1994, PP.8-13)

5- Baer, et, al. study in America in 1995:

Standard and supplementary scales designed to detect underreporting of symptoms on the MMPI and the MMPI-2 were studied with 50 individuals who completed the MMPI-2 under fake-good instructions and 50 who has standard instructions. Two supplementary scales were valuable in discriminating standard from underreported profiles. (Baer, et, al., 1995, pp. 419-23)

6- Bagby, et. al. study in America in 1995:

Result from 344 college students and 129 psychiatric patients supported the effectiveness of the MMPI-2 Infrequency scale in detecting fake-bad responding and the usefulness of the MMPI-2 Obvious-Subtle index, Positive Malingering scale, and Lie scale in detecting fake-good responding. (Bagby, et, al., 1995, pp 84-92)

7- Arbisi and Ben-Porath's study in America in 1995:

The development and initial validation of a new MMPI-2 scale designed to determine infrequent responding with psychopathological populations are described. Results with1,179 subjects with high base rates of psychopathology and psychological distress. (Arbisi \& Ben-Porath, 1995, pp. 424-31)

8- Wetter, et. al. study in 1996:

The ability of persons faking posttraumatic stress disorder or head injury to respond consistently across serial testing on the MMPI-2 was studied with 118 undergraduates. Results suggest that the test takers can fake and describe symptoms consistently, and that type of disorder may affect temporal response consistently. (Wetter, et. al., 1996, pp. 39-47).

9- Berry, et.al. study in 2001:

MMPI-2 results were compared in 118 psychiatric outpatients given standard instructions, instructions to exaggerate their problems, instructions to feign a disorder they did not have, or instructions to feign a global psychological disturbance. The groups were comparable on demographic, occupational and diagnostic characteristics as well as intake MMPI-2 results. Experimental MMPI-2 results showed that the clinical scales were generally elevated in the feigning groups, with only modest differences across dissimulating instructions sets. The feigning groups had reliably higher scores than controls on the overreporting indexes examined, although no significant differences between feigning groups were present for overreporting indexes. (Berry, 2001, pp296-314) 


\section{Results and Conclusion}

1- What is the reason behind students' faking good?

The results showed that the reason behind students' faking good is that they resort to choose 'false' as a response for most of the inventory's items.

In the fake-good response set, the $\mathrm{L}$ and $\mathrm{K}$ scales are likely to be elevated significantly, and the $\mathrm{T}$ score on the $\mathrm{F}$ scale may be below 50 .

The researchers found 50 out of 55 answer sheets included "false" option for most of the items.

2- What is the reason behind students' faking bad?

The results showed that the reason behind students' faking bad is that they resort to choose 'true' as a response for most of the inventory's articles.

In the fake-bad response set, the $\mathrm{F}$ scale are likely to be elevated significantly, and the $\mathrm{T}$ score on the $\mathrm{K}$ and $\mathrm{L}$ scales are may be below 50 .

The researchers found 98 out of 105 answer sheets included "true" option for most of the items.

3- What is the form of Faking Good profiles for males and females separately?

Table 1 shows the mean and the standard deviations for males and females in the first responsiveness form (faking good).

Insert Table 1

Insert Figures 1 \& 2

The Figures 1 and 2 of faking good for males and females show the following:

A- Elevation of $\mathrm{L}$ and $\mathrm{K}$ scales more than $50 \mathrm{~T}$-score.

B- The $\mathrm{T}$ score of the F scale is less than 50 .

C- lower score on most of the clinical scales.

Two forms are similar when comparing faking good male's form with female's, except the elevation of scale 5(Masculinity-Femininity) in female's form. Which indicate women who may be rejecting a very traditional female role, and are likely to be interested in sports, hobbies, and other activates that are stereotypically more masculine than feminine.

This study supports too many studies such as Graham's (1991) Berry's (1992); which indicates that culture have no role in the profile's forms of faking good.

4- What is the form of Faking Bad profiles for males and females separately?

Table 2 shows the mean and the standard deviations for males and females in the second responsiveness form (faking bad).

Insert Table 2

Insert Figures 3 \& 4

The Figures, 3 and 4, of faking bad for males and females show the following:

A- Very Elevated F scale T score (usually well above 100).

B- The $\mathrm{T}$ score of the $\mathrm{L}$ and $\mathrm{K}$ scales is less than 50 .

C- Scores on the clinical scales are very elevated, with scales 6 (paranoia) and 8 (schizophrenia) typically being the most elevated. Scales 5 (Masculinity-Femininity) and 0 (social introversion) typically are the least elevated clinical scales.

Two forms are similar when comparing faking bad male's form with females'.

This study supports too many studies such as Graham's (1991) Rogers, et. al. (1997); which indicates that culture have no role in the profile's forms of faking bad.

It can be said that the reason behind students' faking good and bad is the choosing the choice 'true' or 'false' to the items of the inventory; maybe, they cannot read well enough to understand the items but are reluctant to inform the examiner that this is the case. Other times test takers are confused or uncooperative because they do not want to take the test but feel that they cannot directly refuse to do so, or they are trying to deny problems they suffer from. 


\section{References}

Arbisi, P. \& Ben-Porath, Y. (1995). An MMPI-2 Infrequent Response Scale for Use with Psychopathological Populations: The Infrequency-Psychopathology Scale, "F(p)". Psychological Assessment, Vol. 7, No. 4, Dec., p.424-31.

Austin, J. (1992). The Detection of Fake Good and Fake Bad on the MMPI-2. Educational and Psychological Measurement, Vo. 52, No. 3, Fall, p.669-74.

Baer, R. et al. (1995). Sensitivity of MMPI-2 Validity Scales to Underreporting of Symptoms. Psychological Assessment, Vol. 7, No. 4, Dec., p.419-23.

Bagby, M. et al. (1995). Relative Effectiveness of the Standard Validity Scales in Detecting Fake-Bad and Fake-Good Responding. Psychological Assessment, Vol. 7, No. 1, Mar., p.84-92.

Berry, D. \& Cimino, C. (2001). MMPI-2 Fake-Bad Scales: An Attempted Cross-Validation of Proposed Cutting Scores for Outpatients. Journal of Personality Assessment, Vol. 76, No. 2, p.296-314.

Graham, J. (2000). MMPI-2 Assessing Personality and Psychopathology, Third Edition. Oxford University Press, Inc.

Hathaway, S. \& McKinley, J. (1989). MMPI-2, Manual and Scoring. University of Minnesota Press.

Lamb, D. et al. (1994). Effects Two Types of Information on Malingering of Closed Head Injury on The MMPI-2. Psychological Assessment, Vol. 6, No. 1, Mar., p.8-13.

Parker, W. (1991). The Detection of the Fake Good Response Set on the MMPI-2. 13p.; Paper presented at the Annual Meeting of the Mid-South Educational Research Association (20th, Lexington, Ky, November 12-15, 1991).

Wetter, M. \& Deitsch, S. (1996). Faking Specific Disorders and Temporal Response Consistency on the MMPI-2. Psychological Assessment, Vol. 8, No. 1, Mar., p.39-47.

Wetter, M. et al. (1992). Sensitivity of MMPI-2 Validity Scales to Random Responding and Malingering. Psychological Assessment, Vol. 4, No. 3, Sep., p.369-74.

Table 1

\begin{tabular}{|l|l|l|l|l|}
\hline & \multicolumn{2}{l}{ Mean } & \multicolumn{2}{l}{ Standard deviation } \\
\hline & $\begin{array}{l}\text { Males } \\
\mathrm{N}=20\end{array}$ & $\begin{array}{l}\text { Females } \\
\mathrm{N}=35\end{array}$ & \multicolumn{2}{l|}{ Males } \\
\hline $\mathrm{L}$ & 8.31 & 7.78 & 2.80 & 2.23 \\
\hline $\mathrm{F}$ & 4 & 3.94 & 1.79 & 2.22 \\
\hline $\mathrm{K}$ & 18.09 & 17.94 & 2.38 & 2.94 \\
\hline $\mathrm{Hs}$ & 5.50 & 6.34 & 3.05 & 4.14 \\
\hline $\mathrm{D}$ & 20.86 & 22.89 & 4.36 & 3.99 \\
\hline $\mathrm{Hy}$ & 21.63 & 23.07 & 5.17 & 4.89 \\
\hline $\mathrm{Pd}$ & 15.95 & 16.65 & 4.32 & 4.35 \\
\hline $\mathrm{MF}$ & 22.40 & 30.57 & 4.10 & 3.97 \\
\hline $\mathrm{Pa}$ & 8.45 & 9.26 & 2.68 & 3.02 \\
\hline $\mathrm{Pt}$ & 8.40 & 10.18 & 4.61 & 4.72 \\
\hline $\mathrm{Sc}$ & 9.63 & 11 & 3.87 & 5.29 \\
\hline $\mathrm{Ma}$ & 16.68 & 16.73 & 3.60 & 3.59 \\
\hline $\mathrm{Si}$ & 24.86 & 26.13 & 7.95 & 4.86 \\
\hline
\end{tabular}


Table 2 .

\begin{tabular}{|l|l|l|l|l|}
\hline & \multicolumn{2}{l|}{ Mean } & \multicolumn{2}{l|}{ Standard deviation } \\
\hline & $\begin{array}{l}\text { Males } \\
\mathrm{N}=41\end{array}$ & $\begin{array}{l}\text { Females } \\
\mathrm{N}=64\end{array}$ & Males & Females \\
\hline $\mathrm{L}$ & 4.58 & 4.66 & 1.85 & 1.74 \\
\hline $\mathrm{F}$ & 23.58 & 23.01 & 4.74 & 4.17 \\
\hline $\mathrm{K}$ & 7.47 & 7.29 & 2.60 & 2.78 \\
\hline $\mathrm{Hs}$ & 13.47 & 14.18 & 3.88 & 4.25 \\
\hline $\mathrm{D}$ & 26.33 & 27.83 & 4.15 & 4.64 \\
\hline $\mathrm{Hy}$ & 22.87 & 23.29 & 4.99 & 4.95 \\
\hline $\mathrm{Pd}$ & 24.08 & 26.09 & 4.21 & 4.57 \\
\hline $\mathrm{MF}$ & 24.56 & 27.71 & 4.28 & 3.89 \\
\hline $\mathrm{Pa}$ & 18.20 & 19.36 & 4.49 & 3.80 \\
\hline $\mathrm{Pt}$ & 29.56 & 30.56 & 4.27 & 4.81 \\
\hline $\mathrm{Sc}$ & 40.22 & 40.60 & 6.67 & 6.64 \\
\hline $\mathrm{Ma}$ & 25.54 & 25.22 & 4.22 & 4.11 \\
\hline $\mathrm{Si}$ & 36.16 & 37.30 & 5.94 & 6.10 \\
\hline & & & & \\
\hline
\end{tabular}

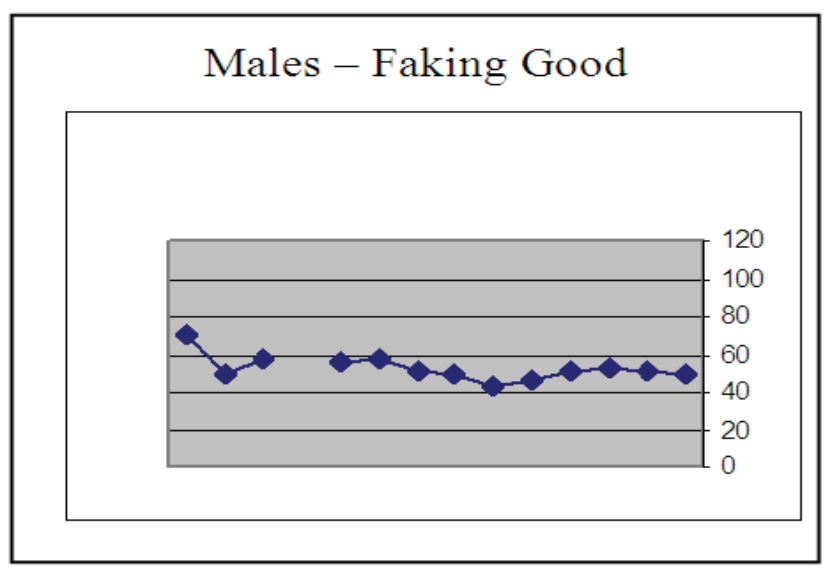

Figure 1. The fake- good profile for males

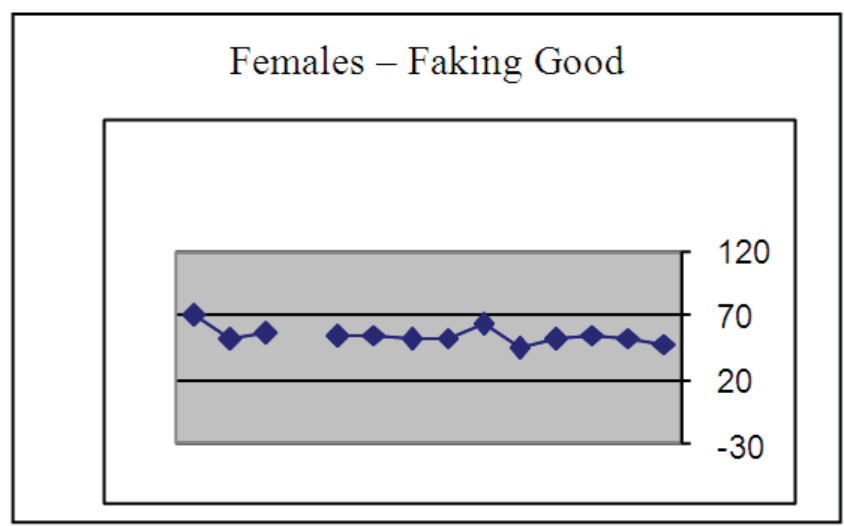

Figure 2. The fake- good profile for females 


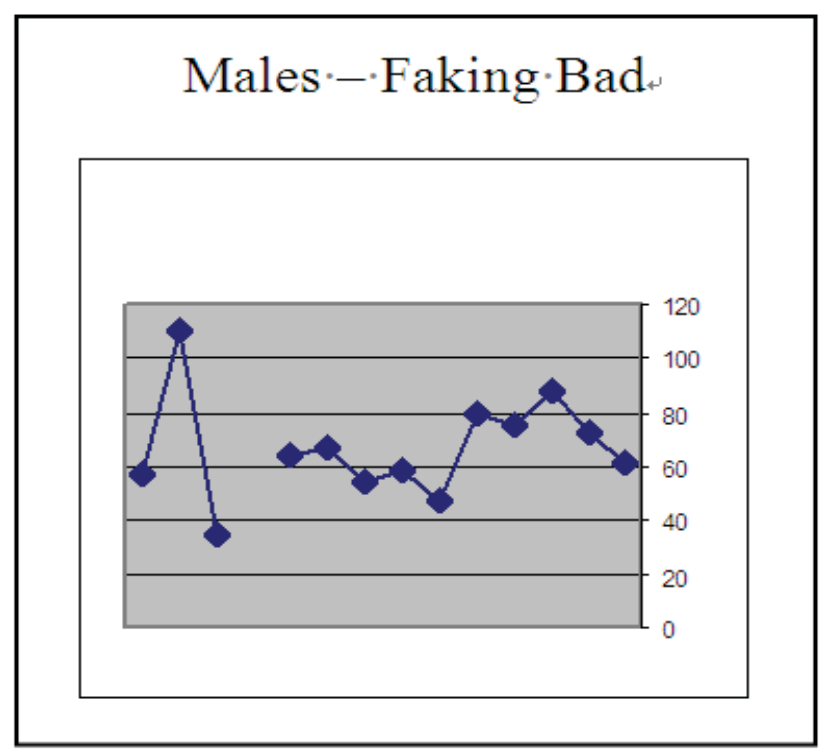

Figure 3. The fake- bad profile for males

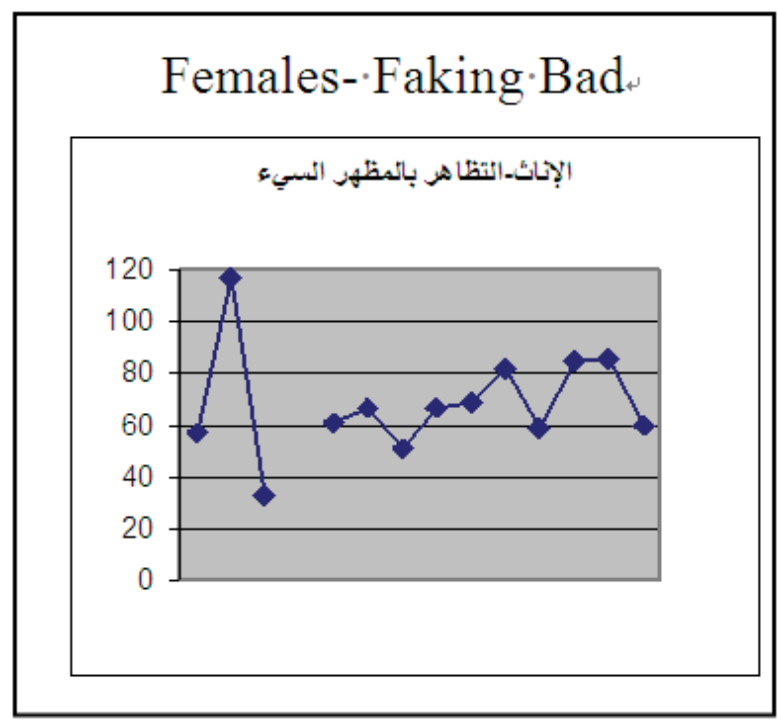

Figure 4. The fake- bad profile for females 